\title{
O BOCA A BOCA: AS CONVERSAÇÕES E A VOZ DO CONSUMIDOR NAS REDES SOCIAIS VIRTUAIS - ESTUDO DE CASO DA MARCA ABERCROMBIE
}

\author{
The mouth-to-mouth: Conversation(s) and the consumer voice in virtual \\ networks - The Abercrombie brand case study
}
El boca a boca: Las conversaciones y la voz del consumidor en las redes sociales virtuales - Estudio de caso de la marca Abercrombie

Marcelo Pereira da Silva

Docente do Mestrado Profissional em Comunicação da Universidade Federal do Maranhão. marcelosilva_rp@hotmail.com

Vânia Braz de Oliveira Coordenadora do curso de Jornalismo da UNIVAP. vaniajor@univap.br

Resumo: O consumidor contemporâneo potencializa sua expressão avaliando as marcas e transmitindo opiniões sobre elas nas redes sociais digitais. É neste ambiente de interatividade que reside nosso objeto de estudo: O boca a boca on-line. Caracterizamos o buzz on-line como um novo fluxo comunicacional que altera a percepção das marcas, demonstrando como, mesmo no habitar virtual, a comunicação, muitas vezes, é unidirecional. Selecionamos o caso da marca Abercrombie, ocorrido em 2015. Por meio da análise de conteúdo categorizamos as falas manifestadas pelos consumidores na fanpage da empresa no Facebook, inferindo que as organizações ainda utilizam a cultura do massivo e precisam considerar ipso facto o complexo fluxo comunicativo da sociedade em rede.

Palavras-chave: Comunicação. Abercrombie. Boca a boca on-line.

Abstract: Contemporary consumers leverage their expression, evaluating brands and conveying opinions about them on on-line social networks. It is in this environment of interactivity that our object of study resides: on-line word of mouth. We characterize on-line buzz as a new communication flow that alters brand awareness, demonstrating how, even in virtual living, communication is often unidirectional. We have selected the Abercrombie brand case in 2015. Through content analysis, we categorize the statements made by consumers in the company fan page on Facebook, inferring that organizations still use the culture of the masses and need to look ipso facto at the current communicative flow of society network.

Keywords: Communication. Abercrombie. The mouth-to-mouth on-line.

Resumen: El consumidor contemporáneo potencializa su expresión, evaluando y transmitiendo opiniones sobre ellas en las redes sociales digitales. Es en este ambiente de interactividad que reside nuestro objeto de análisis: el boca a boca on-line. Lo caracterizamos como un nuevo flujo comunicacional que cambia la percepción de las marcas, demostrando como, incluso en el habitar virtual, la comunicación, muchas veces, es unidireccional. Elegimos el caso de la marca Abercrombie, que sucedió en 2015. A través del análisis de 
contenido categorizamos las hablas manifestadas por consumidores en la fanpage de la empresa en el Facebook, infiriendo que las organizaciones aún usan la cultura de lo masivo y necesitan mirar ipso facto al complejo flujo comunicativo de la sociedad en red.

Palabras-clave: Comunicación. Abercombrie. El boca a boca on-line.

\section{INTRODUÇÃO}

A amplificação da voz do consumidor na sociedade contemporânea apresenta-se como temática cada vez mais relevante nos estudos da comunicação organizacional. Sua utilização, já estabelecida em nosso cotidiano, nos permite, por exemplo, organizar, transformar, processar e propagar as informações em velocidade e capacidade cada vez maiores e com custos cada vez mais reduzidos.

Nesse cenário, nos deparamos com o crescente acesso e distribuição de conteúdo facilitados pelas tecnologias de comunicação que permitem a conexão em rede, apresentandose como um processo comunicativo interativo no qual a distinção entre emissor e receptor é substituída por uma interação de fluxos informativos (DI FELICE, 2017). É neste ambiente de participação e interatividade que está nosso objeto da pesquisa, o boca a boca on-line, também conhecido como uma manifestação informativa pessoal levada a cabo pelos sujeitos nas redes sociais on-line (RECUERO, 2013; TEIXEIRA, 2013; CREMADES, 2009).

O sujeito contemporâneo potencializa suas expressões, pois tornou-se capaz de avaliar uma marca, serviço ou produto e transmitir sua opinião acerca deles. Tudo isto se passa em um ambiente virtual por meio de novas formas de se relacionar, ou seja, uma estrutura de relacionamento entre consumidores e organizações/marcas na qual o boca a boca on-line se fortalece em função das possibilidades de conexão, interatividade e compartilhamento.

Precisamos pensar em como conviver, interagir e relacionar nesse novo ambiente, pois nas redes sociais virtuais existe um espaço para exploração de múltiplas ações de comunicação. Cada vez mais, as organizações/marcas devem estar atentas à ascensão das novas socialidades engendradas pelo habitar on-line (DI FELICE, 2017) e dialogar com o sujeito contemporâneo que, de maneira consciente ou não, pode influenciar seus pares com experiências, percepções e opiniões, o que justifica a proposta temática deste artigo.

Pesquisas bibliográficas iniciais nos levaram à construção dos pressupostos: (P1) as organizações/marcas ainda se valem da cultura do massivo, dialogando pouco com seus 
consumidores, pois utilizam as redes sociais digitais ${ }^{1}$ de forma unidirecional, e (P2) não estão levando em conta o atual fluxo no qual se evidencia a opinião compartilhada dos consumidores, materializando a opinion sharing ${ }^{2}$ e, com isso, tornando as marcas mais vulneráveis (GALINDO, 2012).

Objetivamos aferir nossos pressupostos e caracterizar o boca a boca on-line por meio de uma análise de conteúdo do caso da marca Abercrombie ${ }^{3}$, demonstrando que as redes sociais on-line, apesar de se tipificarem por condições habitativas reticulares e interativas (CORRÊA, 2016), constituindo-se de públicos cada vez mais céticos e conectados, muitas vezes, podem ser utilizadas em um ambiente de comunicação unidirecional e funcionalista em um tempo marcado pela colaboração, participação e expressão de múltiplas vozes.

\section{O CONSUMIDOR NO CENÁRIO CONTEMPORÂNEO}

Galindo (2015) descreve a possibilidade de receber, produzir e compartilhar informações rapidamente acerca de uma marca, um produto, uma pessoa e/ou uma instituição (parceiros e concorrentes). Isto ocorre em virtude das tecnologias da informação, processamento e comunicação que se tornaram o cerne das transformações vividas pelo consumidor contemporâneo em uma sociedade de redes e conectada, a qual caracteriza-se por estruturas abertas capazes de expandir-se de modo ilimitado, desde que compartilhem os mesmos códigos de comunicação.

Cada vez mais, os sujeitos se organizam em redes, mas mediadas por computadores, permitindo uma comunicação híbrida em rede, seja on-line ou off-line com base em interesses, valores, idiossincrasias e afinidades. Para Cardoso (1998, on-line), “estamos na presença de uma nova noção de espaço em que físico e virtual se influenciam um ao outro, lançando as bases para a emergência de novas formas de socialização, novos estilos de vida" e de organização social. As redes são práticas humanas antigas, se transformando em redes ligadas pela Internet, permitindo flexibilidade e, ao mesmo tempo, complexidade e expressão individualizada em uma comunicação global, multicanal e horizontal (CORRÊA, 2016).

\footnotetext{
${ }^{1}$ Utilizamos os termos redes sociais virtuais, redes sociais on-line, redes sociais da Internet e redes sociais digitais como sinônimos, cônscios de que há linhas conceituais que os diferenciam.

2 Optamos por utilizar o termo conceitual em inglês utilizados pelos autores Wolf (2002) e Lazarsfeld (2006) ao se referirem a uma conversação sem imposições.

${ }^{3}$ É uma rede de lojas de vestuário inaugurada em 1892, nos Estados Unidos, que se tornou, no século XX, extremamente popular por vender produtos esportivos para a elite norte-americana.
} 
Esta comunicação global e multicanal faz parte de um espaço público no qual os indivíduos atuam como receptores coletivos de informação, mesmo a informação final sendo processada pelo indivíduo, obedecendo às suas características pessoais. Isto equivale ao êxito do indivíduo que, agora, reconstrói sua interação social com a ajuda de tecnologias da comunicação, pois no espaço virtual o sujeito realiza uma comunicação livre e é capaz de criar seu caminho na rede, produzindo e publicando sua própria informação, portanto, como um sujeito oposto à passividade antes lhe outorgada.

Frente às identidades variadas em curto espaço de tempo, fluidas e vorazes, está o consumidor contemporâneo que, "equipado de suportes tecnológicos irá mostrar suas preferências individuais antes que qualquer outra coisa" (GALINDO, 2012, p. 22). Os suportes tecnológicos possibilitam ao consumidor mobilidade e poder de se manifestar sem a necessidade de um mediador. Este consumidor se converte de um participante passivo para um consumidor ativo. Este sujeito híbrido, antes tratado como um ser amorfo com ações e reações previsíveis, hoje, é visto como um sujeito social relacional. Firat e Christensen (2005, p.223-224, tradução nossa), corroboram essa visão, afirmando que "os receptores não são alvos passivos, mas participantes criativos na produção de experiências e identidades ${ }^{4}$.

Esses consumidores ativos possuem ferramentas cada vez mais poderosas de atualização, comparação e avaliação, trocando e compartilhando informações, opiniões e percepções com seus pares. Dessa forma, são estimulados a manifestar explicitamente seus desejos e individualidades. Esse sujeito está presente e possui múltiplas possibilidades de escolha, se permitindo construir o próprio espaço-tempo por meio da interatividade.

Primo conceitua o sujeito nesse espaço como interagente, ou seja, emana da ideia de interação (ação ou relação que acontece com os participantes), como "aquele que age com o outro" (PRIMO, 2003, p.8), haja vista que as pessoas desejam informação na mídia, mas também necessitam ver-se, ouvir-se falar sobre sua cotidianidade para si e para os indivíduos com os quais convivem, seja no mundo on-line, seja no off-line (MAFFESOLI, 2004).

\section{O BUZZ DO CONSUMIDOR NAS REDES SOCIAIS VIRTUAIS}

Os sujeitos se adaptaram aos novos tempos, utilizando as redes virtuais para formar padrões de interação e criar novas formas de socialidade e organização social (RECUERO,

\footnotetext{
4"And that their intended receivers are not passive targets but creative partners in the production of experiences and identities" (FIRAT; CHRISTENSEN, 2005, p.223-224).
} 
2011). Por conseguinte, a tecnologia da comunicação permite a liberdade e o relacionar característico da sociedade em rede, possibilitando o expressar do consumidor nas redes sociais on-line, ocorrendo certa inversão de poder. Antes, a 'fala' própria dos grandes grupos de mídia e das corporações, agora, cede lugar à 'fala' também do sujeito-consumidor, emergindo uma série de conversações que estabelecem relações e constroem "laços sociais que vão estruturar os grupos sociais e a sociedade como um todo" (RECUERO, 2013, p.53).

Segundo Marcuschi (2003, p. 14), a conversação "é a primeira das formas de linguagem a que estamos expostos e provavelmente a única da qual nunca abdicamos pela vida afora"; na esteira desse pensamento, acreditamos que essas interações, muitas vezes, são feitas, ainda, de forma tradicional, através do boca a boca, mas se utilizando das tecnologias de comunicação como suporte. Este processo comunicacional de interação sempre existiu, visto que as redes sociais existem desde quando havia seres humanos para criá-las. Quando as pessoas ainda viviam em cavernas e viajavam em clãs e tribos, estas eram as redes sociais confiáveis (SAFKO; BRAKE, 2010).

Recuero (2013) assevera que essa conversação em rede adquire as características dos chamados públicos em rede, a saber: a) a permanência das interações, no sentido de que aquilo que foi publicado permaneça acessível no site; b) a buscalidade, característica que refere à capacidade de busca das mensagens nas ferramentas, que é também consequência da permanência; c) a replicabilidade das mensagens, gerada justamente pela permanência e aumento da buscalidade; d) a presença das audiências invisíveis, ligada à característica da escalabilidade das redes.

Essa interação também se observa na oralidade e se define como boca a boca por Arndt (1967, p. 292, tradução nossa): “[...] uma comunicação oral e pessoal entre um emissor percebido como não comercial e um receptor, tratando de uma marca, um produto ou um serviço oferecido para venda",5, concebida, na Internet, por meio de trocas de mensagens predominantemente textuais, que se propagam com mais rapidez, já que os sujeitos se encontram mais interligados (CHETOCHINE, 2006).

Para Breazeale (2009), o boca a boca ganha sua versão eletrônica e busca o compartilhamento e a interatividade. Conforme Goldsmith e Horowitz (2006, p.1, tradução nossa), “a comunicação boca a boca on-line é um processo complementar à comunicação

\footnotetext{
5"He characterized WOM as oral, person-to-person communication between a receiver and a communicator whom the receiver perceives as non-commercial, regarding a brand, product or service".
} 
face-a-face" ${ }^{\prime \prime}$, mesmo que não seja entre os mesmos locutores. Hennig-Thurau (2004, p.39, tradução nossa), afirma que a comunicação boca a boca on-line é "como qualquer declaração positiva ou negativa feita por potenciais, reais, ou ex-clientes sobre um produto ou empresa, que se faz disponível para uma multidão de pessoas e instituições através da Internet"?. Assim, essa troca de informações de marketing desempenha uma função crucial na mudança de atitudes, opiniões e comportamentos dos consumidores concernente a produtos, marcas e serviços.

Para Kaijasilta (2013, p.13, tradução nossa) ${ }^{8}$ nove elementos são identificados para que haja uma comunicação boca a boca on-line (figura 1):

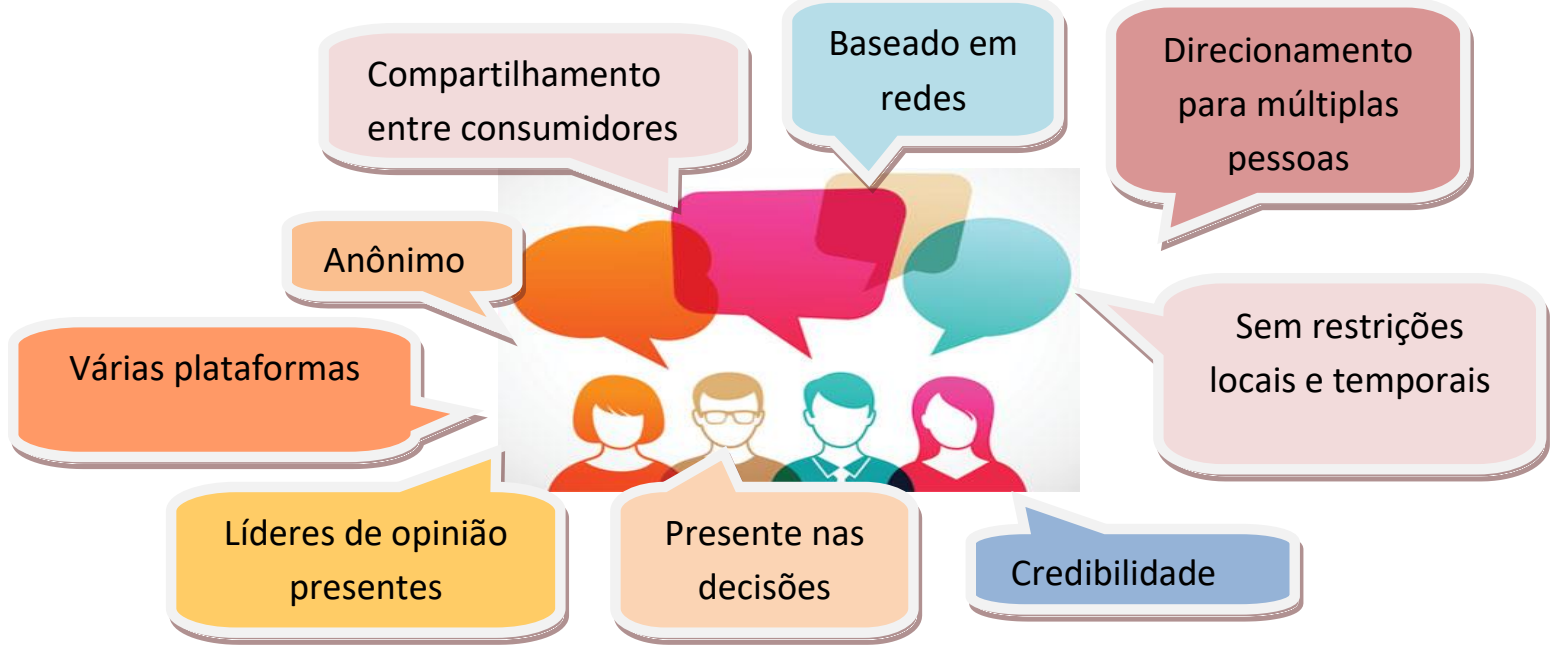

Figura 1- Elementos para uma comunicação boca a boca on-line. Fonte: Kaijasilta (2013, p. 14). Adaptado pelos autores, 2016.

Segundo Jones, Aikem e Boush (2009), o habitar virtual possibilita que os consumidores troquem opiniões, ou seja, reúnam informações de outros consumidores e ofereçam seus próprios conselhos, envolvendo-se eletronicamente. Isso funciona como uma rota para influência social - processo em que os indivíduos fazem alterações em seus

\footnotetext{
6"Highlight the importance of the eWOM investigation as an extension of the traditional face-to-face communication" (GOLDSMITH; HOROWITZ, 2006, p.1).

7“"Any positive or negative statement made by potential, actual, or former customers about a product or company, which is made available to a multitude of people and institutions via the Internet" (HENNIG-THURAU, 2004, p.39).

8"Based on this analysis, nine main elements for eWOM communication can be identified. Electronic word-ofmouth is opinion sharing between consumers about experiences (1) and opinion leaders have an influential role in the content sharing process (2). The interaction happens via the Internet/on-line through different platforms (3), is network-based, (4) and directed to multiple people (5). Electronic word-of-mouth is interaction without time and location constrains (6) and it can be anonymous (7). Because of the on-line environment, there may occur credibility issues that users consider (8). Still, Electronic WOM is increasingly present in consumers' decision process (9)" (KAIJASILTA, 2013, p.13).
} 
pensamentos, sentimentos, atitudes ou comportamentos que resultam da interação com outras pessoas on-line. É o fluxo do boca a boca agora nas redes sociais on-line. A esse respeito Terra (2010) assevera que independentemente da posição das organizações, é fato que os usuários comentam sobre marcas, produtos, serviços e experiências em espaços on-line.

Estas questões relevam nosso objeto teórico e empírico, colocando na ribalta a necessidade de analisarmos casos, conversações e reverberações que decorrem de conteúdos produzidos por consumidores e organizações no universo on-line, nos levando a (re)pensar a comunicação multidirecional que os fluxos midiáticos gerados nas/pelas redes sociais da Internet produz (PRIMO, 2003).

\section{A COMUNICAÇÃO MULTIDIRECIONAL DO HABITAR ON-LINE}

Katz e Lazarsfeld (2006) marcam os estudos da comunicação pela abordagem dos "efeitos limitados", apontando que não só os meios influenciam, mas, também, outras forças dentro da estrutura social medeiam o conteúdo produzido e distribuído pelos meios. Segundo eles, essa mediação ${ }^{9}$ era feita pelos líderes de opinião que tinham o poder de influenciar a opinião de pequenos grupos. Isso refletia nos formadores de opinião que ocupavam um lugar relevante na transmissão e disseminação da informação.

Observando essa teoria, Wolf (2002) afirma que é importante realçar que o contexto social a que ela se refere era diferente do atual. Ele diz que, com a chegada da TV, os líderes de opinião ficam "quase que completamente dispensados da sua função de filtro, em consequência da difusão dos temas, informações e opiniões" (WOLF, 2002, p.58). Ademais, diz que a maior parte das mensagens das comunicações de massa é recebida de forma direta, não necessitando do líder de opinião para ser difundido no nível de comunicação interpessoal, apresentando-se como uma conversa sobre o conteúdo dos meios de massa, o que ele chama de opinion-sharing.

Nesse sentido, Galindo (2015) se atenta ao paradoxo que surge na sociedade em rede, na qual o conteúdo produzido on-line pelos indivíduos que interagem se disponibiliza em volume semelhante ao da mídia massiva, de um para muitos, mas que, agora, cada indivíduo potencializa suas expressões com seus pares, com seus agrupamentos ou comunidades, de muitos para muitos, fazendo com que uma marca ou produto modifique/altere, também, sua forma de se relacionar com seus consumidores.

${ }^{9}$ Conceituamos a mediação como ação de servir de intermediário ou de ser o que serve de intermediário. 
Antes, tínhamos apenas em um meio comunicacional unidirecional voltado para a massa, hoje, atuamos com um meio multidirecional com manifestações massivas quando milhares de pessoas acessam as redes sociais on-line de forma individualizada, ou seja, temos um meio massivo com acesso individualizado. Assim, pelos novos meios, os indivíduos deixaram de lado a forma passiva de recepção de informações dos meios tradicionais para resgatar o receptor que se impõe, negocia e participa, haja vista que a revolução digital implica no surgimento e ampliação de formas "individualizadas de produção, difusão e estoque de informação [...] e a circulação de informações “[...] não obedece à hierarquia da árvore (um-todos) e sim a multiplicidade do rizoma (todos-todos) (LEMOS, 2004, p.68).

O surgimento da Internet ampliou os fluxos informativos, criando múltiplos níveis de produção e circulação de conteúdo. Para Kayahara e Wellman (2007), ao invés de haver apenas a relação entre os meios de comunicação de massa e os líderes de opinião - indivíduos -, há múltiplas relações, em diferentes ordens, entre esses personagens, visto que na medida em que os sujeitos recebem recomendações de seus contatos interpessoais, as reúnem e "trazem essa informação de volta para seus laços", retornando à web para checar as novas informações que seus contatos têm a fornecer ${ }^{10}$ (KAYAHARA; WELLMAN, 2007, p.824, tradução nossa).

Malini (2007) destaca o conceito de opinião distribuída, resultante de múltiplas interações em redes sociais virtuais. Nessa esteira, Kayahara e Wellman (2007) afirmam que essas interações ensejam, novamente, a conversa - a opinion sharing -, e não a imposição, o que faz legitimar um modelo comunicacional favorecido pela variedade de trocas, da colaboração e do compartilhamento.

$\mathrm{O}$ indivíduo que tinha a função de influenciador ou instrumento de passagem da influência da comunicação de massa, hoje, assume o lugar de emissor, produtor e receptor participativo, em um processo que é, ao mesmo tempo, dialógico e dialogal. Isso representa a oportunidade para que os sujeitos utilizem as redes sociais on-line contra as organizações/marcas e/ou, a seu favor. Um dos grandes desafios deste cenário é relacionar-se, ativamente, por meio do diálogo e da conversação. $\mathrm{O}$ acesso à tecnologia traz à tona uma pluralidade de vozes: o boca a boca foi amplificado pelas redes sociais digitais, como analisamos no caso da marca norte-americana de roupas para o público jovem Abercrombie.

\footnotetext{
10"Whereby people receive recommendations from their interpersonal ties, gather information about these recommendations on-line, take this information back to their ties, and go back to the Web to check the new information that their ties have provided them".
} 


\section{O CASO ABERCROMBIE, O BUZZ E AS CONVERSAÇÕES VIRTUAIS}

A história da Abercrombie começa entre o final do século XIX e início do século XX, quando, em 4 de junho de 1892, em Manhattan, o engenheiro David Thomas Abercrombie fundou a marca que, inicialmente, era procurada por caçadores, por isso o símbolo de um alce em suas peças de roupas. Quase cem anos depois, a empresa se estabeleceu com mais de 1.000 lojas e um faturamento superior a 3 bilhões de dólares anuais. Foi em 1996, com a chegada de Mike Jeffries ao posto de presidente do Conselho, que a marca investiu em peças jovens e "descoladas".

Mike Jeffries deu início à expansão da marca em 2006, quando ousou vender em catálogos eróticos e se recusou a produzir roupas em tamanhos maiores ( $G$ ou GG), desconsiderando um mercado mundial de grande demanda em ascensão, que é a categoria Plus size ${ }^{11}$. Nesta época, Mike Jeffries, em entrevista para o site de notícias Salon disse:

Em toda escola há adolescentes que são legais e populares, e há aqueles que não são tão legais. Nós estamos atrás dos legais. Nós vamos atrás de todos os adolescentes atraentes com muita atitude e muitos amigos. Muitas pessoas não pertencem às nossas roupas, e elas nem podem pertencer. Nós somos excludentes? Absolutamente". (ÉPOCA NEGÓCIOS, 2013, ON-LINE).

Em seguida, uma onda de protestos na porta das lojas Abercrombie, nos Estados Unidos, se iniciou, repercutindo, também, no Brasil. A indignação não se limitou ao público feminino acima do peso ou às páginas do Facebook. O americano Greg Karber, de Los Angeles, começou uma campanha para que peças da marca fossem doadas para moradores de rua. No Brasil, o estudante de design Isaias Zatz distribuiu as primeiras peças na região dos Campos Elísios, Santa Cecília, na capital paulista.

Diante da reverberação do caso, a marca viu-se obrigada a se manifestar nas redes sociais virtuais. No Facebook, o CEO da marca, Mike Jeffries, publicou uma "Nota de Esclarecimento", no dia 15 de maio de 2013, dias depois do assunto ter ganhado capilaridade e engajamento nas redes, gerando 1.200 compartilhamentos e mais de 3,7 mil comentários.

\footnotetext{
${ }^{11}$ Em 2018, o mercado brasileiro de vestuário, por exemplo, para tamanhos acima de 46, movimentou $\mathrm{R} \$ 7,2$ bilhões, registrando crescimento de $8 \%$. O número de lojas físicas especializadas em plus size, em território nacional, é de 12.305, seguido de 632 negócios digitais, de acordo com a Associação Brasileira de Plus Size (ABPS).
} 


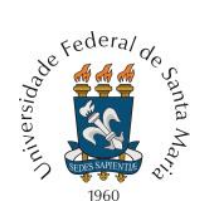

PROGRAMA DE PÓS-GRADUAÇÃO EM COMUNICAÇÃO DA UNIVERSIDADE FEDERAL DE SANTA MARIA

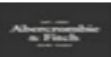

Abercrombie \& Fitch

15 de maio de $2013-\Theta$

1. Curtir Página

A note from Mike, our CEO

I want to address some of my comments that have been circulating from a 2006 interview. While I believe this 7 year old, resurrected quote has been taken out of context, I sincerely regret that my choice of words was

interpreted in a manner that has caused offense. A\&F is an aspirational brand that, like most specialty apparel brands, targets its marketing at a particular segment of customers. However, we care about the broader communities in which we operate and are strongly committed to diversity and inclusion. We hire good people who share these values. We are completely opposed to any discrimination, bullying, derogatory characterizations or other anti-social behavior based on race, gender, body type or other individual characteristics.

Uma nota de Mike, nosso CEO:

Quero abordar alguns dos meus comentários que estão circulando em uma entrevista. 2006 Enquanto eu acredito neste 7 anos de idade, resurrected citação foi retirado do contexto, lamento sinceramente que minha escolha de palavras foi interpretada de forma que causou ofensa. Um e fé uma marca que aspira a uma solução, como a maioria das marcas de vestuário especialidade, metas seu marketing em um determinado segmento de clientes. No entanto, nos preocupamos com as grandes comunidades em que estamos inseridos e estão muito empenhados na diversidade $e$ inclusăo. Vamos contratar pessoas boas que compartilhar esses valores. Somos totalmente contra a qualquer tipo de discriminação, bullying, derrogatório characterizations ou outros comportamento anti-Social com base na raça, sexo, corpo tipo ou outras

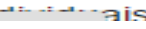

Figura 2 - Nota de Michael Jeffries (CEO Abercrombie).

Fonte: Facebook, Abercrombie, 2013.

O boca a boca on-line é uma prática de comunicação autônoma e livre que representa um emergente fluxo comunicacional entre consumidores e organizações, potencializado pelas novas tecnologias da comunicação, podendo alterar a percepção da marca e demonstrar que o uso que as marcas fazem das redes sociais virtuais, ainda ocorre sob os auspícios de um modelo unidirecional.

Para nossa análise, usamos como método de pesquisa o Estudo de Caso com foco para a marca Abercrombie, escolhido por meio de uma amostragem por conveniência. Assim, como corpus de nossa análise, selecionamos os comentários dos consumidores sobre o fato que apresentamos durante sete dias após postagem da nota de esclarecimento da marca no Facebook (quadro 1).

\begin{tabular}{|c|c|}
\hline Fanpage & Período de postagem /análise \\
\hline Abercrombie & 15 de maio até 22 de maio de 2013 \\
\hline
\end{tabular}

A metodologia utilizada para analisarmos o caso, ou seja, a conversação - o boca a boca - nas redes sociais virtuais em relação à volta, para o mundo on-line, do comentário de 2006 do CEO da marca Abercrombie, Mike Jeffries, foi a análise de conteúdo. Para tanto, estabelecemos algumas categorias para tornar a investigação mais didática, a saber: 


\section{Categoria A: A fala do consumidor on-line referente à marca.}

Esta categoria se subdivide em:

- Críticas depreciativas (comentários concebidos ao uso de palavras ou expressões que remetem o consumidor a um sentimento de diminuição em relação à marca);

- Críticas construtivas (comentários concebidos ao uso de palavras ou expressões que remetem o consumidor a um sentimento de construção, colaboração);

- Ação social favorável (comentários concebidos ao uso de palavras ou expressões que remetem o consumidor a uma ação social favorável à marca);

- Ação social contrária (comentários concebidos ao uso de palavras ou expressões que remetem o consumidor a uma ação social contrária à marca).

\section{Categoria B: A fala do consumidor on-line referente ao conteúdo do post exibido.}

Esta categoria se subdivide em:

- Igualitária (palavras ou expressões em concordância com o conteúdo);

- $\quad$ Contrária (palavras ou expressões em discordância do conteúdo publicado);

- $\quad$ Embasada (comentários com base em especialistas);

- Comparativa-igualitária (comentários com base em relatos de outros consumidores do grupo em concordância com o conteúdo);

- Comparativa-contrária (comentários com base em relatos de outros consumidores do grupo em discordância do conteúdo);

Todos os comentários contidos após postagem da "Nota de Esclarecimento" foram separados, apresentando como número absoluto 3.700 comentários (100\%), sendo 3.667 (99\%) durante o período selecionado (tabela 1).

Tabela 1 - Dias X quantidade de comentários analisados - Abercrombie.

\begin{tabular}{c|c|c|c|c|c|c|c|c}
\hline Data & $\mathbf{1 5 / 0 5 / 2 0 1 3}$ & $\mathbf{1 6 / 0 5 / 2 0 1 3}$ & $\mathbf{1 7 / 0 5 / 2 0 1 3}$ & $\mathbf{1 8 / 0 5 / 2 0 1 3}$ & $\mathbf{1 9 / 0 5 / 2 0 1 3}$ & $\mathbf{2 0 / 0 5 / 2 0 1 3}$ & $\mathbf{2 1 / 0 5 / 2 0 1 3}$ & $\mathbf{2 2 / 0 5 / 2 0 1 3}$ \\
\hline Com. & 1188 & 1127 & 610 & 332 & 179 & 103 & 68 & 60 \\
\hline$\%$ & $32,7 \%$ & $30,7 \%$ & $16,6 \%$ & $9 \%$ & $4,8 \%$ & $2,8 \%$ & $1,8 \%$ & $1,6 \%$ \\
\hline
\end{tabular}

Fonte: Os autores, 2016. 
Os dados descritos a seguir refletem os 3.667 (100\%) comentários analisados no Facebook, em suas subcategorias, sendo Críticas Depreciativas (9,6\%), Críticas Construtivas (1\%), Ação Social Favorável (0\%), Ação Social Contrária (8\%), Igualitárias (5,9\%), Comparativa Igualitária (3,3\%), Contrária $(46,6 \%)$, Comparativa Contrária $(5,1 \%)$ e Embasada (0,5\%), o que totaliza $80 \%$ dos comentários analisados, restando $20 \%$ que foram excluídos por se tratarem de comentários materializados em forma de emotions e outros.

Iniciamos nossa análise pela Categoria A e suas subcategorias, onde os comentários extraídos no Facebook refletem percepções negativas sobre a marca, com mais de 9\% dos comentários pertencentes à subcategoria "críticas depreciativas" (tabela 2), enquanto apenas $1 \%$ refere-se às "críticas construtivas".

Destacamos algumas palavras e expressões selecionadas na subcategoria "críticas depreciativas", tantos referentes ao CEO quanto à marca. Os comentários concernentes à empresa podem ser exemplificados tais como: “A\&F é uma marca 'aspiracional' que agora está engasgando com o próprio vômito (sic)", "Como pode uma marca que opera a nível mundial (sic), ter sido tão estúpida? Inacreditável!

Tabela 2 - Categorias/Críticas depreciativas (Facebook) - Abercrombie.

\begin{tabular}{lll}
\hline Total de comentários & 3667 & $100 \%$ \\
\hline Críticas depreciativas & 355 & $9,6 \%$ \\
Marca discriminatória & & \\
Marca não me representa & & \\
Marca de m* & & \\
Bando de incompetentes & & \\
Nojento & \\
Idiotas & \\
Racistas & \\
Preconceituosos & \\
Insensível
\end{tabular}

Fonte: Os autores, 2016.

Em algumas falas acerca da marca e do CEO, encontramos ponderações dos responsáveis pela comunicação da marca: "Isso não é apenas vender para um público-alvo. Isso é RP RUIM (sic)". As críticas construtivas também apareceram nesta análise, mas em número bem inferior, chegando à casa de $1 \%$ dos comentários analisados. Nesta subcategoria, os comentários se referem exclusivamente à marca e não ao $\mathrm{CEO}$, tais como: " $A A \& F d e$ fato não discrimina”, “Adoro A\&F”, "Marca responsável, tenta dizer a verdade”.

Junto às críticas construtivas e depreciativas, destacamos outra subcategoria nesta parte da análise: “Ação social contrária”, ou seja, comentários concebidos ao uso de palavras ou expressões que remetem o consumidor a uma ação social contrária à marca. Com $8 \%$ dos 
comentários destinados a essa subcategoria, totalizando 297, as ações vão desde a recusa pela compra até a convocação para outros movimentos como apresentamos na tabela 3:

Tabela 3- Categorias/Ação social contrária (Facebook) - Abercrombie.

\begin{tabular}{lll}
\hline Total de comentários & 3667 & $100 \%$ \\
\hline Ação social contrária & 297 & $8 \%$ \\
Boicote à marca & & \\
Não compre & & \\
Não use & & \\
Doe aos sem teto & \\
'Descurta' a página & \\
Compartilhe as ações & \\
\#FitchOsSemTeto & & \\
\hline
\end{tabular}

Fonte: Os autores, 2016.

Esses "boicotes" passam pelo boicote econômico (quando observamos nos comentários a relação com os preços das peças), boicote de minorias (quando em comentários está clara a exclusão por estar acima do peso), boicote social (pela marca estar em desacordo com as práticas no que tange aos funcionários) e, por fim, o boicote relacional (um ato de punição à empresa quando não há uma relação adequada entre as partes). Para Cruz (2013), tanto o boicote relacional quanto o social, surgem de motivações ideológicas e evidenciam o lugar ativo do consumidor em virtude dos fluxos reticulares de informação, a emergência de uma cultura da participação/conexão e a mudança nas lógicas de visibilidade e legitimação (DI FELICE, 2017; CREMADES, 2009; GALINDO, 2012; CORRÊA, 2016; PRIMO, 2003).

Em nossa análise, nenhuma ação favorável que pudesse gerar percentual foi observada.

Desta feita, continuamos a análise da Categoria B, agora sob uma perspectiva negativa referente ao conteúdo da postagem, ou seja, a subcategoria "Contrária", que sobressai em relação às outras com mais de $46 \%$ dos comentários analisados.

Muitos comentários contrários à postagem do CEO parecem ter sido apagados, pois há outros que nos remetem a observações tais como: "Eu atingi eles... eles escondem meus comentários, eles são covardes e temem críticas haha"(sic), "Vão em frente e continuem apagando meus comentários (sic)", "Estão apagando porque, é o medooooo!! (sic)”. Juntamente com as reclamações sobre os comentários que podem ter sido apagados, encontramos muitas mensagens contrárias à publicação ou "retratação" do CEO, completamente descrentes do conteúdo publicado, tais como: "Eu não acredito nessa besteira. Esse comentário não é apropriado ou inclusivo em nenhum contexto (sic)”. 
No que se refere à subcategoria "Comparativa contrária" (comentários com base em relatos de outros consumidores do grupo em discordância do conteúdo publicado), temos pouco mais de $5 \%$ do total dos comentários analisados, separados por palavras iniciais que referenciam comentários de outros membros do grupo contrários ao conteúdo do post veiculado pelo CEO: “Certo. Porque nós vamos acreditar totalmente nele agora. Sarcasmo com certeza (sic)".

Mesmo com quase a metade das postagens contrárias à declaração, há um número de comentários favoráveis ao conteúdo postado por Mike Jeffries, muitos deles alegando compreender a postura da empresa e também do CEO. Podemos exemplificar com os trechos a seguir: “As pessoas podem, por favor, esquecer essas declarações. Elas são incrivelmente velhas. Por que elas foram ressuscitadas à toa da internet? Então algum jornalista patético precisava de uma estória e decidiu pegar declarações VELHAS e colocar palavras na boca do Mike? A A\&F é a favor da diversidade e inclusão (sic)”.

Já na subcategoria "Comparativa Igualitária" (comentários com base em relatos de outros consumidores do grupo em concordância com o conteúdo publicado), observamos certa troca de comentários correspondentes à visão do conteúdo publicado pelo CEO, mesmo que em um número pequeno (3,3\%). Comentários como: "Concordo com vcs. Eu vou comprar na sua loja não importa o que acontecer porque eu amo seus produtos (sic)", etc.

Os conteúdos publicados pelos consumidores mostram que o boca a boca on-line faz parte de uma realidade sociotecnica que produz a necessidade urgente de as organizações/marcas lidarem eficazmente com as crises e conflitos decorrentes de um contexto de ubiquidade, conexão, interatividade, cocriação, despolarização do polo de emissão e comunicação colaborativa, etc. e lança luz à complexidade da ecologia na comunicação digital na sociedade contemporânea (AIKEM E BOUSH, 2009; RECUERO, 2013; LEMOS, 2014; CARDOSO, 1998; BREAZEALE, 2009; GOLDSMITH E HOROWITZ, 2006; HENNIG-THURAU, 2004).

\section{CONCLUSÕES}

Os resultados da análise sobre o caso Abercrombie e os comentários gerados após publicações do post no Facebook sugerem algumas conclusões sobre opinion-sharing e o fluxo de comunicação construído pelo consumidor contemporâneo, tais como: 
a) A presença da conversação nas redes sociais on-line entre os participantes que expressam suas opiniões e as compartilham. É essa conversação que possibilita a geração de outros conteúdos, podendo chegar ao universo off-line. Ainda que seja apenas uma amostra, o volume de conteúdo extraído das conversações revela as opiniões, percepções, o compartilhamento e o micropoder (CREMADES, 2009) do consumidor contemporâneo;

b) A conversação se realiza em um ambiente on-line, no qual os participantes têm a possibilidade de dialogar com outros e se reconhecerem pela posição favorável ou contrária ao conteúdo exposto, sem imposições, resultado do capital social construído pelas/nas redes sociais virtuais;

c) $\mathrm{O}$ fluxo comunicacional da sociedade em rede sai do modelo unidirecional para o multidirecional, ou seja, não produzimos e compartilhamos de um para um ou de um para muitos, mas de muitos para muitos, já que todos são emissores e receptores. Todo o conteúdo pode ser modificado, personalizado e compartilhado por uma plateia heterogênea;

d) O fluxo comunicacional unidirecional ainda é utilizado, como no caso em análise, já que a marca não dialoga com aqueles que deveriam ser tratados como "iguais", por meio de um processo de conversação e não imposição.

Todos os comentários expressos e analisados na amostra recolhida se harmonizam com a conversação (sem fins comerciais) ou a opinion sharing (WOLF, 2002; LAZARSFELD, 2006). Em uma sociedade digitalizada na qual a tecnologia e o acesso permitem que as pessoas assumam um atitude mais participativa, as redes sociais on-line se tornam relevantes, inclusive como objeto de investigação, visto que evidenciam um sujeito formador de opinião, produtor de conteúdo e portador de micropoder (TERRA, 2010; CREMADES, 2009; GALINDO, 2012); as organizações/marcas precisam estar atentas para dialogar com esse consumidor e implantar estratégias ligadas à urgência do diálogo, da colaboração e interatividade nessa nova ecologia midiática (DI FELICE, 2017; CORRÊA, 2016).

Nesse cenário cuja lógica é o ser autônomo e participativo que interage e gera relacionamentos, em nossa análise, não observamos uma relação dialógica e dialogal entre o consumidor e a Abercrombie. Constatamos que a cultura do massivo ainda está impregnada nas práticas de algumas organizações, dado que se utilizam das mídias digitais apenas como meio de divulgação de conteúdo, restringindo sua potencialidade de diálogo, conversa aberta e honesta, o que não aconteceu no caso que analisamos.

Devemos reforçar, contudo, que não é suficiente apenas interagir. É necessário estar em tempo real, ouvir, se sensibilizar, assumir erros e buscar a conciliação de interesses para 
que seja possível traçar estratégias de relacionamento e negócios voltadas para o consumidor. Percebemos que, em nenhum momento, no caso analisado, a organização se manifestou, mesmo apoiada em dados gerados pelos comentários expostos em sua página.

Não ouvir e/ou ficar calado é uma forma de comunicação que pode gerar crises e conflitos, pois demonstra desinteresse pela opinião, percepções, experiências e demandas do outro. O consumidor contemporâneo espera que com as redes sociais on-line as organizações/marcas coloquem em prática a aproximação, participação, autorreconhecimento e interatividade.

A urgente necessidade de relações de confiança, disponibilidade/disposição para ouvir, negociar, conversar e interagir, democraticamente, com respeito e abertura, tipifica a realidade que emerge com o surgimento, a ampliação dos fluxos e atores on-line, capital social fundamental para os estudos das conversações e do buzz próprios das redes sociais virtuais.

\section{REFERÊNCIAS}

ARNDT, Johan. Role of product related conversations in the diffusion of a new product. Journal of Marketing Research, v. 4, p. 291-295, Aug. 1967. Disponível em: $<$ http://www.jstor.org/discover/10.2307/3149462?uid=3737664\&uid=2\&uid=4\&sid=21103897265 653>.Acesso em: 04 mar. 2014.

BREAZEALE, Michael. Word of mouse.An assessment of electronic word-of-mouth research. International Journal of Market Research, v. 51, n. 3, p. 297-318, 2009. Disponível em:<http://www.researchgate.net/publication/220012942_Word_of_Mouse_An_Assessment_of_Elect ronic_Word-of-Mouth_Research>.Acesso em: 04 mar. 2014.

CARDOSO, Gustavo. Contributos para uma sociologia do ciberespaço. Disponível em: http://bocc.ubi.pt/pag/cardoso-gustavo-sociologia-ciberespaco.html. Acesso em: 04 de jan. 2016.

CHETOCHINE, Georges. Buzz Marketing: sua marca na boca do cliente. 1.ed. São Paulo: Prentice Hall Brasil, 2006.

CORRÊA, Elisabeth Saad. A comunicação na sociedade digitalizada: desafios para as organizações contemporâneas. In: KUNSCH, Margarida Maria Krohling (Org). Comunicação Organizacional Estratégica - aportes conceituais e aplicados. São Paulo: Summus, 2016. p.59-76.

CREMADES, Javier. Micropoder: a força do cidadão na era digital. Tradução de Edgard Charles. São Paulo: Senac São Paulo, 2009.

CRUZ, Breno de P. A. O boicote no comportamento do consumidor.Tese (Doutorado) - Escola de Administração de Empresas de São Paulo, São Paulo, 2013.

DI FELICE, Massimo. Net-Ativismo: Da ação social para o ato conectivo. Paulus: São Paulo, 2017. 
Para afastar gordas Abercrombie se recusa a fazer roupas largas. EPOCA NEGÓCIOS. https://epocanegocios.globo.com/Inspiracao/Empresa/noticia/2013/05/para-afastar-gordasabercrombie-se-recusa-fazer-roupas-largas.html. Acesso em 29 de junho de 2019.

FIRAT, A; CHRISTENSEN, L. T. Marketing communications in a postmodern world. In: KIMMEL, A. J. (Ed.). Marketing communication. New York: Oxford University, 2005, p.211-236.

GALINDO, Daniel S. El consumidor postmoderno, uma persona relacional - anclajes conceptuales. Madrid: Fragua, 2012.

GALINDO, Daniel S. A comunicação de mercado e o paradoxo dos atributos e benefícios em uma sociedade relacional. In: GALINDO. Daniel S. (Org). A comunicação de mercado em redes virtuais: uma questão de relacionamento. Chapecó: Argos, 2015. p. 1-55.

HENNIG-THURAU, Thorten et al.Electronic word-of-mouth via consumer-opinion platforms: what motivates consumers to articulate themselves on the internet? Journal of Interactive Marketing, v. 18, n. 1, p. 38-52, 2004.Disponível em:

<http://www.marketingcenter.de/lmm/research/publications/hennig-thurau.html>. Acesso em: 03 jan. 2015.

JENSEN, Rof. The dream society: how the coming shift from information to imagination will transform your business. McGrall Hill Educations, E-book, 2001.

JONES, S. A.;AIKEN, K.; BOUSH, D. M. Integrating experience, advertising, andelectronic word of mouth. Journal of Internet Commerce, v. 8, n. 3-4, p. 246-267, 2009. Disponível em:

$<$ http://libra.msra.cn/Publication/37343792/integrating-experience-advertising-and-electronic-wordof-mouth>. Acesso em: 03 jan. 2015.

KAIJASILTA, Nina. International design business management master's thesis.2013. Alto University School of Ecnomics, 2013. Disponível em:

<http://epub.lib.aalto.fi/en/ethesis/pdf/13398/hse_ethesis_13398.pdf>. Acesso em: 03 Jan. 2015.

KAYAHARA, Jennifer; WELLMAN, Barry.Searching for culture: high and low.Journal of Computer-Mediated Communication, 2007.Disponível em: <http://onlinelibrary.wiley.com/doi/10.1111/j.1083-6101.2007.00352.x/epdf >. Acesso em: 03 set. 2015.

KATZ, Elihu; LAZARSFELD, Paul F. Personal influence: the part played by people in the flow of mass communications. $2^{\text {nd }}$. ed. New Jersey: Transactions Publishers, 2006.

LEMOS, André. Cibercultura: tecnologia e vida social na cultura contemporânea. Porto Alegre: Sulina. 2004.

LIPOVETSKY, Gilles. A felicidade paradoxal: ensaio sobre a sociedade de hiperconsumo. Tradução de Maria Lúcia Machado. São Paulo: Companhia das Letras, 2007.

MAFFESOLI, Michel. Mediações simbólicas: a imagem como vínculo social. In:MARTINS, Francisco M.; SILVA, Juremir Machado da (Orgs). Para navegar no século XXI. 3.ed. Porto Alegre: Sulina/Edipucrs, 2003. p.37-48.

MAFFESOLI, Michel. A comunicação sem fim (teoria pós-moderna da comunicação). In: MARTINS, Francisco Menezes; SILVA, Juremir Machado da (Orgs.). A genealogia do virtual: comunicação, cultura e tecnologias do imaginário. Porto Alegre: Sulina, 2004. 
MALINI, Fábio. A opinião pública distribuída: blogs e jornalismo nas eleições brasileiras de 2006.Revista da Associação Nacional dos Programas de Pós-Graduação em Comunicação, ago. 2007. Disponível em: <http://compos.org.br/seer/index.php/e-compos/article/viewFile/181/182>. Acesso em: 04 abr. 2015.

MARCUSCHI, Luiz Antônio. Análise da conversação. 5.ed. São Paulo: Ática,2003. Mercado Plus Size não conquistou nem $10 \%$ de seu potencial, segundo ABPS. Associação Brasileira Plus Size. Disponível em: https://www.pictame.com/user/abpsoficial/4178827532. Acessado em: 10 de maio de 2019.

PRIMO, Alex. Quão interativo é o hipertexto? Da interface potencial à escrita coletiva. Fronteiras: Estudos Midiáticos, São Leopoldo, v. 5, n. 2, p. 125-142, 2003.

RECUERO, Raquel. Redes sociais na internet. 2.ed. Porto Alegre: Sulina, 2011.

RECUERO, Raquel. Nó3 - Atos de ameaças à face e à conversação em redes socais na Internet. In: PRIMO, Alex (Org.). Interações em rede. Porto Alegre: Salina, 2013. p.51-70.

RODRIGUES, Catarina. Blogs e a fragmentação do espaço público. Livros Labcom, E-book, 2006. Disponível em: <http://www.livroslabcom.ubi.pt/pdfs/20110824-

rodrigues_catarina_blogs_fragmentacao_espaco_publico.pdf>. Acesso em: 02 maio 2015.

SAFKO, Lon; BRAKE, David K. A Bíblia da mídia social: táticas, ferramentas e estratégias para construir e transformar negócios. Tradução de James Gama. São Paulo: Blucher, 2010.

TEIXEIRA, Patrícia Brito. Caiu na rede. E agora? Gestão de crises nas redes sociais. São Paulo: Évora, 2013.

TERRA, Carolina F. Usuário-mídia: a relação entre a comunicação organizacional e o conteúdo gerado pelo internauta nas mídias sociais. 2010. 217f. Tese (Doutorado em Ciências da Comunicação) - Escola de Comunicações e Artes, Universidade de São Paulo, 2010.

WOLF, Mauro. Teorias da comunicação. Tradução de Maria Jorge Vilar de Figueiredo. 7.ed.Lisboa: Presença, 2002.

\section{Original recebido em: 08 de junho de 2018 \\ Aceito para publicação em: 18 de junho de 2019}

Marcelo Pereira da Silva

Pós-doutor em Comunicação pela UNESP. Docente permanente do Mestrado Interdisciplinar em "Cultura e Sociedade", do Mestrado Profissional em Comunicação e do curso de Relações Públicas da Universidade Federal do Maranhão. Coordenador do Grupo de Pesquisa Ecologia da Comunicação Organizacional - ECCOM

Vânia Braz de Oliveira Doutora em Comunicação pela Universidade Metodista de São Paulo, Coordenadora do curso de Jornalismo da UNIVAP, membro dos Grupos de Pesquisa ECOM/UMESP e 


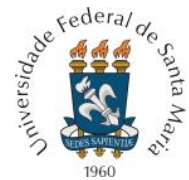

PROGRAMA DE PÓS-GRADUAÇÃO EM COMUNICAÇÃO DA UNIVERSIDADE FEDERAL DE SANTA MARIA

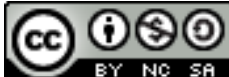

Esta obra está licenciado com uma Licença

Creative Commons Atribuição-NãoComercial-CompartilhaIgual 4.0 Internacional 